\title{
Great Moderation and Great Recession: From plain sailing to stormy seas? *
}

\author{
María Dolores Gadea ${ }^{\dagger}$ \\ University of Zaragoza
}

\author{
Ana Gómez-Loscos $\ddagger$
}

Bank of Spain

September 2015

\section{Gabriel Pérez-Quirós ${ }^{\S}$}

Bank of Spain and CEPR

\begin{abstract}
Many have argued that the Great Recession of 2008 marks the end of the Great Moderation of the eighties and nineties. This paper shows this is not the case through painstaking empirical analysis of the data. Output volatility remains subdued despite the tumult created by the Great Recession. This finding has important implications for policymaking since a lower volatility of output (the hallmark of the Great Moderation) is associated with lower recoveries.
\end{abstract}

JEL classification: C22, E32

Keywords: business cycle, volatility, recoveries

${ }^{*}$ We are very grateful to participants at Banco de España seminars, ESEM 2013, IIIt Workshop in Time Series Econometrics 2013, CFE-ERCIM 2013 Conference, IEA World Congress 2014, Barcelona GSE Summer Forum 2014, SNDE Conference 2015 and IAAE Annual Conference 2015 for their comments and suggestions. M. Dolores Gadea acknowledges financial support of the Ministerio de Ciencia y Tecnología under grant ECO2011-30260-C03-02. The views expressed in this paper are the responsibility of the authors and do not necessarily represent those of the Banco de España or the Eurosystem.

${ }^{\dagger}$ Department of Applied Economics, University of Zaragoza. Gran Vía, 4, 50005 Zaragoza (Spain). Tel: +349767 61842, fax: +34976761840 and e-mail: lgadea@unizar.es

${ }^{\ddagger}$ Bank of Spain, Alcalá, 48, 28014 Madrid (Spain). Tel: +34 91 3385817, fax: +34 915310059 and e-mail: agomezloscos@bde.es

${ }^{\S}$ Bank of Spain, Alcalá, 48, 28014 Madrid (Spain). Tel: +34 91 3385333, fax: +34 915310059 and e-mail: gabriel.perez@bde.es 


\section{Introduction}

The period of unusually stable macroeconomic activity experienced in the United States during the last decades of the 20th century is known as the Great Moderation (GM, henceforth). Kim and Nelson (1999) and McConnell and Perez-Quiros (2000) were the first to document the substantial decline in US output volatility ${ }^{1}$ in the early $1980 \mathrm{~s}^{2}$, although it was in Stock and Watson (2002) that the term was coined. Bernanke (2004), in a speech at the meeting of the Eastern Economic Association (then a member of the Board of Governors of the Federal Reserve but soon to become the chairman), brought this finding to the attention of a wider public.

The literature on the GM has been and still is very prolific. In particular, as is well known, its possible causes have received a great deal of attention and continue to be a matter of lively debate as the academic profession has so far failed to provide a consensus on the relative importance of the various explanations. The explanations fall into three categories, namely, changes in the structure of production, improved policy and good luck ${ }^{3}$.

One basic macroeconomic consensus before the recent economic crisis was that the GM was a virtually permanent phenomenon. Blanchard and Simon (2001) concluded that "The decrease in output volatility appears sufficiently steady and broad based that a major reversal appears unlikely. This implies a much smaller likelihood of recessions...". Lucas (2003), in his Presidential address to the AEA stated that the "central problem of depression-prevention has been solved, for all practical purposes" and Bernanke (2004) declared "The reduction in

\footnotetext{
${ }^{1}$ This phenomenon of volatility reduction also has an international dimension. Blanchard and Simon (2001) show a decline both in output and inflation variability in the US as well as in other industrial countries. Chauvet and Popli (2008) find that the decrease in US output volatility after 1984 is part of a broader long trend shared by several countries. Summers (2005) and Stock and Watson (2005) also find the structural break for the G7 and Australia.

${ }^{2}$ Among the pioneering papers, some date the increased stability in the economy in the first quarter of 1984 (McConnell and Perez-Quiros (2000) and Kim and Nelson (1999)). Others, such as Blanchard and Simon (2001), argue that the moderation of the volatility was probably more gradual. Indeed, they suggest that the large underlying decline in output volatility started in the 1950s.

${ }^{3}$ Examples of this debate can be found in the literature, starting with the papers by Stock and Watson (2002) and Ahmed et al. (2004) until the more recent evidence in Giannone et al. (2008), Justiniano and Primiceri (2008), Canova (2009), Gali and Gambetti (2009), Canova and Gambetti (2010) and Inoue and Rossi (2011), just to quote a few.
} 
the volatility of output is also closely associated with the fact that recessions have become less frequent and less severe". In fact, since 1984, the US had experienced only two relatively mild recessions until the latest ${ }^{4}$, called the Great Recession (GR, henceforth) by the profession.

The GR was of unprecedented severity and duration in the postwar US business cycle and led many economists to conclude that there was a major breakdown in the data generating process of the GDP, meaning that the late-2000s economic and financial crisis may have brought the GM period to an end. Taylor (2012) celebrated in his blog the Five-Year Anniversary of the End of the Great Moderation with such an emphatic statement as "Five years ago this month the GM ENDED. To be precise Dec 2007 is the month in which the NBER designed the peak and it was the end of the Great Moderation and the beginning of the Great Recession". More recently, Blanchard (2014) has expressed "Until the 2008 global financial crisis, mainstream US macroeconomics had taken an increasingly benign view of economic fluctuations in output and employment. The crisis has made it clear that this view was wrong and there is a need for a deep reassessment".

Indeed, very valuable academic work points to the end of the GM. Most of the papers that consider that the GR meant the end of the GM agree that it was actually the consequence of the disequilibria accumulated during the GM. These disequilibria were due to an excess of confidence and led to excess leverage, which left the economy vulnerable to small shocks to asset prices. This is the argument behind the theoretical models of Brunnermeier and Sannikov (2014) and Brunnermeier et al. (2013) and the transmission mechanism mentioned in these papers has been called "balance sheet recessions". Using a different reasoning, Bean (2010) relates the end of the GM with a misperception of risk. If the GR has broken confidence, as a result of a change in expectations formation (a modification in the transition mechanism), it would not be possible to return to the stable structure that existed before, bringing the GM clearly to an end. Williams and Taylor (2009) and Taylor (2011, 2012) claim that the GM has ended because of the "Great Deviation", a set of measures implemented

\footnotetext{
${ }^{4}$ The National Bureau of Economic Research (NBER) identifies the following three recessions since the beginning of the GM: 1990.3-1991.1, 2001.1-2001.4, 2007.4-2009.2.
} 
by the Fed between 2003 and 2010 that contradicted the standard monetary policy rules and were the primary cause of inflating disequilibria that eventually caused the GR. Finally, Carvalho and Gabaix (2013) focus on sectoral diversification and descend to microeconomic firm-level to understand the swings in macroeconomic volatility. They find that a decreasing share of the manufacturing sector (the Great Diversification) was the initial cause of GM just as the surge in the size of the financial sector close to the GR has provoked an increase of volatility.

Empirically-oriented papers also conclude that the GM is over. For example, $\mathrm{Ng}$ and Tambalotti (2012) use a dynamic macroeconomic model based on Justiniano et al. (2010) to predict the GR with two different samples (1984-2007 and 1954-2007). They find that they need the wider span to capture the GR. However, if the GM were a permanent phenomenon, the GR should be identified with the first sample, which means that the GM was not so stable, that it was not such a great structural change. Ng and Wright (2013) consider that the new features of the last recessions, in particular, their financial origin, have finally killed the stability associated with the GM. Keating and Valcarcel (2012) investigate the behavior of output growth and inflation volatilities over 140 years for several countries (the US, the UK, Sweden, Italy, Finland, Denmark, Canada and Australia). They find that the financial crisis has completely eroded the stability gains achieved during the GM in almost all the countries they consider.

Against these arguments, Clark (2009), based on a descriptive statistical analysis of volatility, finds that the variabilities of GDP growth and of many sectors of the economy rose significantly after the GR, reversing most of the stability gains of the GM, which could be primarily attributed to larger shocks in oil prices and financial conditions. He argues that, over time, the economy undergoes occasional shifts although low volatility is the norm, which would mean that the GM is not over. A theoretical paper by Coibion and Gorodnichenko (2011) would also support that the GM is not over, depending on whether good policy has played an important role in accounting for the GM. 
The implications for academics and policymakers of whether the GM has ended or continues are as important as the original discovery of the GM. Hakkio et al. (2013) state "An important question for Federal Reserve policymakers and for other policymakers in the United States and worldwide is whether the disruption beginning in 2007 was a temporary blip or reflects a shift to a more volatile economy going forward". More recently, Furman (2014), Head of the Council of Economic Advisors, in a speech at the Annual Hyman P. Minsky Conference called attention to the GM, proposing that "In the wake of the Great Recession, it is worth reassessing the Great Moderation hypothesis and understanding what it means for policy going forward". Therefore, it is not banal to devote statistical efforts to re-visit the timing of the GM after the visit of the GR.

For the academic literature, if the GM still holds, the break in volatility has important implications for widely-used theoretical and empirical techniques, such as, for example, in the estimation of state-space models of business cycle fluctuations, model calibration exercises and the estimation of structural vector autoregression models over periods spanning the break. For policymakers, it is key not only in order to identify the magnitude expected for future expansion periods, but also to examine the likelihood of having a sluggish recovery, to deal with jobless recoveries, to be aware of whether there is any change in business cycle characteristics or to examine the international transmission of business cycles (see Camacho et al. (2011), Stock and Watson (2012), Ng and Wright (2013) and Gali and Backus (1999), respectively).

In this paper, we want to formally address the question of whether the GM still holds. For this purpose, in Section 2, we revisit the results obtained in the seminal paper of McConnell and Perez-Quiros (2000) with the updated sample so as to include the most recent developments associated with the GR. We find that the GM, as it was originally formulated, still holds. However, we want to test the robustness of this result. Firstly, we apply additional econometric techniques that allow the possibility of multiple structural breaks in the volatility of the series (Section 3). Secondly, to test the validity of the results, we perform 
different experiments considering alternative economic scenarios for the future, extending the business cycle features of the GR several periods ahead, concocting the observations of the GR with those of the GM and even simulating processes of higher volatility (Section 4). We note that, even if the GR lasted for a significant period of time, the GM would still remain in force. It would require a long and turbulent period with specific business cycle characteristics, not supported by the data available at present, to overturn the GM. Finally, in Section 5, we show that the GM remaining is linked to the features of expansion periods, we observe that sluggish recoveries are the price paid for low volatility. The implications of the GM remaining after a period of huge turmoil go further of those found in the first discovery and shed some light on the nature of the GM. Obviously, if the GM still holds despite the huge negative shocks that have beaten up the US economy during the GR and after experiencing, as stated in Williams and Taylor (2009) and Taylor (2011, 2012), a "Great Deviation" from optimal policies, something structural about the private sector structure of production should prevail as the primary source of the GM. Therefore, the fact that the GM still holds offers evidence in favor of the explanations of the changes in the structure of the economy proposed in Gali and Gambetti (2009), Camacho et al. (2011) Davis and Kahn (2008) and Vine and Ramey (2006).

\section{The Great Moderation revisited}

Kim and Nelson (1999), in the context of Markov Switching models, and McConnell and Perez-Quiros (2000), within the framework of linear and non linear specifications, find evidence of a break in the volatility of the growth rate of the US real GDP in the first quarter of 1984, both using data from 1953.1 until 1999.2. Bearing in mind the content of the debate in the Introduction, the first question to analyze is whether the GM would still hold with the latest available data, which includes the GR and its recovery. Figure 1 plots GDP growth

rate for this sample. To test for the presence of the GM, McConnell and Perez-Quiros (2000) propose the following specification: 


$$
\begin{gathered}
y_{t}=\mu+\rho y_{t-1}+\epsilon_{t} \\
\sqrt{\frac{\pi}{2}\left|\epsilon_{t}\right|}=\alpha_{1} D_{1 t}+\alpha_{2} D_{2 t}+u_{t} \\
D_{1 t}=\left\{\begin{array}{c}
1 \text { if } t<T \\
0 \text { if } t>T
\end{array}\right\} \\
D_{2 t}=\left\{\begin{array}{c}
1 \text { if } t>T \\
0 \text { if } t<T
\end{array}\right\}
\end{gathered}
$$

where $y_{t}$ is the growth rate of GDP, $\mathrm{T}$ is the estimated break point, and $\alpha_{1}$ and $\alpha_{2}$ are the corresponding estimators of the standard deviation.

The test for a break in volatility is a test of the null hypothesis of $\alpha_{1}=\alpha_{2}$ but, as is well known in the literature, under the null hypothesis, $\mathrm{T}$ is a nuisance parameter that makes the asymptotic properties of the standard tests invalid. Andrews (1993) and Andrews and Ploberger (1994) derive the properties of the tests for cases like this. They propose the function $F n(T)$, where $n$ is the number of observations, defined as the Wald or LM statistic of the hypothesis that $\alpha_{1}=\alpha_{2 n}$ for each possible value of $\mathrm{T}$ and give the asymptotic distribution of the statistic:

$$
\begin{gathered}
F n=\sup F n(T) \\
\exp F n=\ln \left(1 /\left(T_{2}-T_{1}+1\right) * \sum \exp (1 / 2 * F n(T))\right. \\
\text { aveFn }=\left(1 /\left(T_{2}-T_{1}+1\right)\right) * \sum F n(T)
\end{gathered}
$$

The results of these tests for the 1953.2-2013.4 sample are presented in Table 1. As 
can be seen, it is clear that the decline in volatility known as the GM, as it was originally formulated, still holds.

In addition, just to check the robustness of our results and their importance in explaining business cycle features, even after the GR, we estimate, as in McConnell and Perez-Quiros (2000), a Markov Switching model with two independent Markov processes, one for the variance and one for the mean, allowing for different coefficients in the mean conditional on the state of the variance. The results are similar to those obtained in McConnell and Perez-Quiros (2000), where a change in regime of the MS model for the variance is one of the clearest features of the data ${ }^{5}$.

However, the robustness of these results should be tested as there are two important caveats that deserve some attention at this point. First, the tests originally used by McConnell and Perez-Quiros (2000) consider the possibility of only one break point. Other tests later developed in the literature consider the possibility of more than one break point. If the GM has ended with the GR but without replicating the conditions of pre-1984, we could still have a break in 1984 but we would not be able to test if the new characteristics associated with the GR are statistically different from those prevailing during the period 1984-2007.

Second, the GR is relatively short-lived (even considering the subsequent recovery) and an end-of-sample phenomenon. The structural break tests used in the literature are not defined to capture breaks at the end of the sample because the standard break tests need to trim the data at the beginning and at the end of the sample to test for stability in each subsample. Therefore, it is necessary, to check to what extent the GR constitutes a change in regime, to consider different experiments that overcome the problem of the short duration and avoid the end-of-the-sample issue.

The next two sections deal with these issues.

\footnotetext{
${ }^{5}$ In order to save space we do not present the table but it is available upon request.
} 


\section{Multiple Breaks in Mean and Volatility}

A careful look at Figure 1 shows that the overall movement of the business cycle and its intensity appear to have changed over the last 60 years. We can graphically appreciate the postwar economic boom which ended with the oil crisis of the 1970s and its subsequent effects on the economy. In the mid 1980s, a reduction in the volatility of the business cycle series compared to prior periods was observed. During this period, known as the GM, the US enjoyed long economic expansions only interrupted by recessions in 1990-91 and 2001 that were mild by historical standards. The final period of the sample is characterized by the severity of the recession that started in late 2007.

Even though we will concentrate on breaks in the volatility of the variance, we first consider the possibility of a change in the mean: if this change in the mean occurs in the data and we do not take it into account in the specification, we could find, wrongly, a break in the variance due to the misspecification in the mean.

\subsection{Structural breaks in the mean}

To test for the presence of structural breaks in the mean of GDP growth rate, we apply the methodology of Bai and Perron $(1998,2003 \mathrm{a}, \mathrm{b})(\mathrm{BP}, \text { henceforth })^{6}$. Based on the principle of global minimizers of the sum of squared residuals, the BP methodology looks for multiple structural breaks, consistently determining the number of break points over all possible partitions as well as their location. They consider $m$ breaks $(m+1$ regimes) in a general model of the type:

$$
y_{t}=x_{t}^{\prime} \beta+z_{t}^{\prime} \delta_{j}+u_{t}
$$

where $y_{t}$ is the dependent variable, $x_{t}(p x 1)$ and $z_{t}(q x 1)$ are vectors of independent variables of which the first is invariant and the other can change, $\beta$ and $\delta_{j}(j=1, \ldots, m+1)$ are the corresponding vectors of coefficients and $T_{i}, \ldots, T_{m}$ are the break points which are considered

\footnotetext{
${ }^{6}$ Previously, we checked, with a battery of unit root tests, that the US GDP growth is stationary.
} 
endogenous in the model.

We consider two cases, Model 1 with $z_{t}^{\prime}=1$ and $x_{t}^{\prime}=0$, i.e. a model with just one constant, and Model 2 with $z_{t}^{\prime}=1$ and $x_{t}^{\prime}=\left(y_{t-1}\right)$, a standard autoregressive model of order 1. In both cases $y_{t}$ represents the GDP growth rate:

$$
\begin{aligned}
& \text { Model 1: } y_{t}=\delta_{i}+u_{t} \\
& \text { Model 2: } y_{t}=\beta y_{t-1}+\delta_{i}+u_{t}
\end{aligned}
$$

Bai and Perron (1998) propose three types of tests. The supF_(k) test considers the null hypothesis of no breaks against the alternative of $k$ breaks. The $\sup F_{-}(l+1 / l)$ test takes the existence of $l$ breaks, with $l=0,1, \ldots$, as its $H_{0}$, against the alternative of $l+1$ changes. Finally, the so-called "double maximum" tests, UDmax and WDmax, test the null of the absence of structural breaks against the existence of an unknown number of breaks. When the number of breaks is unknown, Bai and Perron (2003a) recommend, as a better option than the supF_(k), the following strategy for the empirical work. They suggest beginning with the sequential test $\operatorname{supF}_{-}(l+1 / l)$. If no break is detected, they recommend checking this result with the UDmax and WDmax tests to see if at least one break exists. When this is the case, they recommend continuing with a sequential application of the $\sup F_{-}(l+1 / l)$ test, with $l=1, \ldots$ In addition, the $S B I C$ information criterion is used to select the number of changing points.

This strategy has been followed to explore the existence of structural breaks in a pure changing model representing the mean of the variables (Model 1) and additionally including an autoregressive term (Model 2). A maximum number of 3 breaks has been considered, which, with a sample size $T=244$, supposes a trimming of $\epsilon=0.10$. The process is allowed to present autocorrelation and heteroskedasticity. The nonparametric correction of Andrews (1991) has been employed to consider these effects. Table 2 shows the results of applying these tests. They all agree that US GDP growth rate does not have any structural change in the mean. 
Although previous tests do not detect any structural changes in the mean, there may be other more subtle forms of instability. Due to the possible existence of a slowdown in the trend of US GDP growth after $\mathrm{WWII}^{7}$, we model the average growth as a time-varying parameter following Stock and Watson (1998):

$$
\begin{aligned}
& y_{t}=\beta_{t}+u_{t} \\
& \Delta \beta_{t}=(\lambda / T) \eta_{t} \\
& u_{t}=\Phi(L) \epsilon_{t}
\end{aligned}
$$

where $\epsilon_{t}$ and $\eta_{t}$ are serially and mutually uncorrelated mean 0 random disturbances, and the GDP growth, $y_{t}$, has a random walk time-varying component with a small variance that depends on $\lambda$. Stock and Watson (1998) propose several median unbiased estimators of $\lambda$ that measure the extent of random-walk time variation and conditional on it, we compute the time-varying trend. Results in Table 3 show that none of the tests proposed by Stock and Watson (1998) reject the null hypothesis of $\lambda=0$ at $10 \%$ level. The values of $\lambda$ are all small, ranging from 3.41 to 7.26 depending of the median unbiased estimates proposed by Stock and Watson(1998), which correspond to values of $\sigma_{\Delta \beta_{t}}$ ranging from 0.02 to 0.04 . Different estimates of the model parameters using the Kalman filter are shown at the bottom of Table $3^{8}$.

Estimates of trend growth rates, $\beta_{t}$, based on these models are displayed in Figure 2. Trends exhibit a small but non-negligible variation over the sample, whose extent depends on the size of $\sigma_{\Delta \beta_{t}}$ estimated in each model ${ }^{9}$. Nevertheless, the downward trend obtained is heavily affected by the GR at the end of the sample. This allows us to stress the importance of the cyclical phase of the economy when measuring major trends in growth, which can lead

\footnotetext{
${ }^{7}$ This idea is pointed to by Stock (2015) and related to the secular stagnation hypothesis proposed by Summers (2014).

${ }^{8}$ The first two, maximum marginal likelihood estimator (MMLE) and maximum profile likelihood estimator (MPLE) differ in the assumptions about the initial value of $\beta_{0}$. We fix the values of $\sigma_{\Delta \beta}$ at 0.04 and 0.15, which correspond, respectively, to the point estimate and the upper end of the $90 \%$ confidence interval, both based on the $L$-test. Following Stock and Watson, we have estimated a model with 4 lags, but results are not sensitive to other orders. Further details in Stock and Watson (1998).

${ }^{9}$ The time-varying trend estimated using the MMLE method is $0.09 \%$.
} 
to erroneous conclusions. In any case, we take these results into account when analyzing volatility.

\subsection{Structural breaks in volatility}

As we mentioned before, the statistical methods used when replicating the results of McConnell and Perez-Quiros (2000), based on Andrews (1993) and Andrews and Ploberger (1994), only consider the possibility of one structural break. If the GM came to an end as a consequence of the irruption of the GR, another break should appear around it $^{10}$. Therefore, it is necessary to consider a methodology that allows for multiple break points. Inclán and Tiao (1994) (IT) proposed a test for the detection of changes in the unconditional variance of the series which belongs to the CUSUM-type test family and has been extensively used, especially on financial series. The test is defined as follows:

$$
\begin{aligned}
I T & =\sup _{k}\left|\sqrt{T / 2} D_{k}\right| \text { where } \\
C_{k} & =\sum_{t=1}^{k} \varepsilon_{t}^{2} \\
D_{k} & =\frac{C_{k}}{C_{t}}-\frac{k}{t} \text { with } D_{o}=D_{T}=0
\end{aligned}
$$

This test assumes that the innovations $\varepsilon_{t}$ of the stochastic processes $y_{t}$ are zero-mean normally, i.i.d. random variables and uses an Iterated Cumulative Sum of Squares (ICSS) to detect the number of breaks. However, Sanso et al. (2004) show that the asymptotic distribution of the IT test is critically dependent on these assumptions. So, the IT test has big size distortions when the assumption of normally distributed innovations fails in the fourth order moment or for heteroskedastic conditional variance processes and, consequently, it tends to overestimate the number of breaks ${ }^{11}$. To overcome this drawback, they propose

\footnotetext{
${ }^{10}$ Andrews (2003) proposes a test to look for structural breaks at the end of the sample. However, it only considers the possibility of one break point.

${ }^{11}$ Deng and Perron (2008) extend the IT approach to more general processes, showing that the correction for non-normality proposed by Sanso et al. (2004) is suitable when the test is applied to the unconditional variance of the raw data. Furthermore, the Montecarlo study carried out by Zhou and Perron (2008) highlights that this procedure is adequate when there are no changes in the mean or other coefficients of the regression; otherwise, the test has important size distortions which increase according to the magnitude of the changes in the mean.
} 
a correction which explicitly takes the fourth order moment properties of the disturbances and the conditional heteroskedasticity into account $\left(I T\left(\kappa_{1}\right), I T\left(\kappa_{2}\right)\right.$, respectively).

$$
\begin{aligned}
& I T\left(\kappa_{1}\right)=\sup _{k}\left|\sqrt{T / B_{k}}\right| \text { where } \\
& B_{k}=\frac{C k-\frac{k}{T} C_{T}}{\sqrt{\widehat{\eta}_{4}-\widehat{\sigma}^{4}}} \\
& \widehat{\eta}_{4}=T^{-1 \sum_{t=1}^{T}} y_{t}^{4}, \widehat{\sigma}^{4}=T^{-1} C_{T} \\
& I T\left(\kappa_{2}\right)=\sup _{k}\left|\sqrt{T / G_{k}}\right| \text { where } \\
& G_{k}=\widehat{\varpi}_{4}^{-1 / 2}\left(C_{k}-\frac{k}{T} C_{T}\right)
\end{aligned}
$$

where $\widehat{\varpi}_{4}$ is a consistent estimator of $\varpi_{4}=\lim _{T \rightarrow \infty} E\left(T^{-1}\left(\sum_{t=1}^{k}\left(\varepsilon_{t}^{2}-\sigma^{2}\right)\right)^{2}\right)$.

As US GDP growth series shares some of the characteristics of the financial series, it is non-mesokurtic with a fat right tail and the conditional variance of the innovations is not constant over time ${ }^{12}$, we use the previous corrections. Table 4 shows the results of applying the $I T\left(\kappa_{1}\right)$ and $I T\left(\kappa_{2}\right)$ tests to the US GDP growth rate. We conclude that there is only one change in variance, in 1984.1. The GR does not represent a structural break in volatility.

This finding is stronger than the results of the previous section where we revisited the GM using the McConnell and Perez-Quiros (2000) approach. Why is that? Suppose that the GR has structurally increased the volatility but not to the level of the pre-GM period. Even if we had a new break in volatility, if we apply the McConnell and Perez-Quiros (2000) approach, we would still find the break of the GM. That is because there is definitely a strong break in the $80 \mathrm{~s}$, and this new additional break, smaller in size, would not send the economy back to the pre-GM volatile period. Since the main conclusions of this work lie in the tests of change in volatility, we must reflect on their robustness. For this, we use alternative tests proposed in the literature.

We compute a well-known procedure within the parametric framework which consists of

\footnotetext{
${ }^{12}$ Fagiolo et al. (2008) find that US GDP growth rates can be approximated by densities with tails much fatter than those of a Normal distribution. This implies that output growth patterns tend to be quite lumpy: large growth events, either positive or negative, seem to be more frequent than a Gaussian model would predict. In fact, the kurtosis of GDP growth ratio is 5.94.
} 
applying a test that looks for changes in the mean of the absolute value of the estimated residuals ${ }^{13}$. Zhou and Perron (2008) show that, if there is an ignored change in the mean of the series, the test suffers from serious size distortions which increase as the magnitude of the change in the mean increases. However, as we have shown in the previous subsection, our series do not have any change in the mean. Therefore, we apply the method of BP to detect structural changes in the absolute value of the residuals. We obtain the same break points as with the IT test. Additionally, we employ the method in McConnell and Perez-Quiros (2000) in a sequential procedure, and find the same number and location of the breaks (Table $4)$.

We have replicated all these procedures with the filtered series obtained by removing the trend growth rates based on the time-varying parameter $\beta_{t}$, estimated with different methods taking into account the uncertainty associated to the estimation of $\sigma_{\Delta \beta_{t}}$ (previous section). We find no difference with respect to the results with the original series (Table 4).

Overall, we do not detect additional breaks, even allowing for more than one break. Therefore, we can clearly conclude not only that the GM still holds, but also that the change in volatility associated with the GR does not represent a sufficient change in the data generating process to be considered "structural".

\section{Focusing on the last few years}

In the previous section, we have analyzed the presence of structural breaks in the mean and the variance of the GDP series. A standard statistical approach to the results show that, even when considering the whole sample, the GM still holds. However, as we mentioned before, it is possible that the GM is over but that we still do not have statistical evidence of its end. In this section, we want to know whether we do not find a break in 2007.4 because such a break does not exist or because there is not enough statistical power to find a break.

\footnotetext{
${ }^{13}$ This method has been used by Herrera and Pesavento (2005) and Stock and Watson (2002), among others.
} 
There are several problems involved in detecting structural breaks associated with the GR. It is relatively short-lived (from 2007.4 until today) even if we consider, as we do, not only the recession itself but also its recovery ${ }^{14}$ which is right at the end of the sample. Even if there were a structural break, these two facts could hide its presence and lead econometricians to erroneously conclude that there is no break. The purpose of this section is to simulate different scenarios to isolate each of the features of the data that could mask an additional structural break associated with the GR.

\subsection{Accounting for end-of-sample issues: Simulating the timing of the Great Recession}

Firstly, we address the end-of-sample issue. In order to deal with this problem, we build artificial series by intercalating the GR data ${ }^{15}$ as a block at each observation of the GM (Experiment 1) and compute the structural break tests as in the previous section ${ }^{16}$. If the structural break associated with the GR is hidden because it is a phenomenon that occurs at the end of the sample, exactly where the standard tests for structural breaks need to trim the data, when the GR data (and its subsequent recovery) are introduced in the middle of the sample, we should find evidence of a structural break wherever these data appear in the sample. We may even find a structural break associated with the GR and a new break related to the return to the GM when the GR data end.

The results of Experiment 1 are computed both with the BP (sequential procedure) and the IT ( $\kappa_{2}$ version) tests (Tables 5 and 6 ). Applying both, the break associated with the GM holds in most cases at $1984.2^{17}$. In some cases, a new break appears instead of the GM one. It should be noted that the GM structural break is displaced some periods ahead and this occurs when we add the GR observations at the beginning of the GM and, therefore,

\footnotetext{
${ }^{14}$ There is a "structural" reason for considering the recovery from the recession. If the GR created a structural break in the data, this break should persist even after the recession period.

${ }^{15}$ Notice that, by GR, we refer to the period from 2008.1 to 2013.4 , that is, the recession and its recovery.

${ }^{16}$ Thus, we obtain a number of artificial series equal to the number of observations of the GM.

${ }^{17}$ We allow a confidence interval of $2.5 \%$ of the sample size around the date, i.e., 6 quarters.
} 
more than a disappearance of the GM, we observe a delay of the same ${ }^{18}$. As has been shown, even changing the order of the GR data, we do not find additional breaks associated with the GR in most cases. Therefore, it is clear that the fact that the GR does not represent an additional break point in the data is not a consequence of its being at the end of the sample.

Just to make sure that the nature of the results does not depend on the timing of the GR, we propose an additional exercise (Experiment 2). In this case, we randomly mix the observations of the GR with those of the GM following the stationary bootstrap techniques proposed by Politis and Romano (1994). This procedure is based on re-sampling blocks of random length from the sample comprising GM and GR where the length of each block has a geometric distribution ${ }^{19}$. As in the previous case, when we look for structural breaks, using both tests, the structural break of the GM is identified in most cases (more than 90\%). In the rest of the cases, either no break appears in the series (applying the BP methodology) or we find a new random break (with the IT procedure). Not even when adding random volatility of the kind of the GR at different moments, do we find an increase in volatility comparable with the pre-GM period.

\subsection{Accounting for the length of the Great Recession: Simulating future growth scenarios.}

Given that we have clearly seen that the failure to detect a new break is not associated with the timing of the GR, the second question is to relate it with the length of the GR. In Experiment 3, we enlarge the duration of the GR and its recovery for 5, 10 and 15 years following the stationary bootstrap techniques used in the previous experiment and look for structural breaks. In most cases, and with both procedures, only the structural break associated with the GM is detected (Tables 5 and 6). To be precise, this happens

\footnotetext{
${ }^{18}$ The GM structural break is delayed some periods ahead when we insert the GR after either of the first ten quarters after the beginning of the GM.

${ }^{19}$ We have selected the probability of the geometric distribution so that its expected value is equal to the average duration of expansions, $\lambda=0.06$, or 16 quarters. We run 10,000 iterations. Results are robust to different values of the $\lambda$ parameter.
} 
in $100 \%$ of the cases for all time horizons using the BP technique. However, with the IT test, although this is the most general case, on some occasions, a period of lower volatility is identified between 1996.1 and 2000.2. This finding is not completely new. McConnell and Perez-Quiros (2000) already find some evidence of additional volatility changes when dividing production by sector, while Alcala and Sancho (2004) also identify an additional volatility reduction, associated with compositional changes, in the mid 90s. Hence, neither does the structural break of 1984.2 disappear nor is a new break found around the GR ${ }^{20}$.

Finally, and in view of these results, we wonder how it would be possible to end the GM. We carry out a counterfactual with different conditions to those of the GR trying to take the GM to an end. In order to do this, we conduct Experiment 4, in which we enlarge the GR and its recovery for 5, 10 and 15 years ahead with the pre-GM business cycle features (instead of those of the GR), using stationary bootstrap techniques, and, once again, look for structural breaks. We find only one break, in 1984.2 in almost $70 \%$ of the iterations using the BP technique ${ }^{21}$ and in $77.3 \%$ with the IT procedure ${ }^{22}$ (Tables 5 and 6). However, for longer time horizons, the structural break linked to the GM disappears in most cases. More precisely, we need 8 years according to the IT test and 6 using the BP test to kill the GM. This lapse was exactly the same needed to detect the structural break associated with the GM, as shown by Camacho and Perez-Quiros $(2007)^{23}$. The most common casuistry after 10 years is either the presence of another break associated with the GR or very close to it ${ }^{24}$

\footnotetext{
${ }^{20}$ Even though we did not find a break in the mean in Section 3.1, we redo the tests for a break in the mean when we enlarge the sample to make sure that the breaks in volatility identified using the BP test are not due to a misspecification in the mean. The results show that, in most cases, there is no break in the mean for the simulated series $(98.8 \%, 90.8 \%$ and $69 \%$ for 5,10 and 15 years, respectively).

${ }^{21}$ In $30 \%$ of the cases, there is another structural break at the beginning of the GR.

${ }^{22}$ In $15.4 \%$ of the cases, another break associated with the GR is found and, in $4.7 \%$, no break at all is detected.

${ }^{23}$ They use the approximation suggested by Hansen (1997) to plot the p-values of the supremum test defined in Andrews (1993) and the exponential and average tests developed in Andrews and Ploberger (1994) to test the structural break in the volatility of GDP growth series successively enlarged with one additional observation during the period 1997.1-2006.4. This figure reveals that a clear signal of the structural break does not appear until the nineties, to be exact, around 1991-1992.

${ }^{24}$ Applying BP, the break around the GR appears $58.4 \%$ of times for 10 years and $53.5 \%$ for 15 years while, with IT, this break is found in $41.4 \%$ of the cases for 10 years and in $27.2 \%$ for 15 years.
} 
or the absence of any structural break ${ }^{25}$.

In short, the results of the experiments are compelling. In no case is the GR a significant change from the existing baseline. Only a turbulent period, lasting 6-8 years and with conditions similar to the pre-GM period could provoke a significant change in the current business cycle features. It seems that the GR has not changed the structural characteristics associated with the GM.

We want to delve deeper into Experiment 4 and reveal what the exact differences between pre GM data and GR data are. Is it just volatility? Notice that the standard deviation of the pre-GM period was 1.12 while, during the GR and its recovery, it was just $0.80^{26}$. However, we are not sure that the differences come just from volatility. To tackle this issue, we conduct Experiment 5, in which we enlarge the sample using the GR data, like in Experiment 4, but incorporating the pre-GM volatility characteristics (with the same bootstrapping techniques and for the previous temporal spans). The results are quite emphatic: the GM still remains in force -that is, only the 1984.2 break is identified- in most cases with both tests and for the three time horizons, although the percentages decrease as we increase the horizon ${ }^{27}$.

In order to check the robustness of our experiments, we run a Monte Carlo exercise. We simulate $i i d$ processes with DGP $y_{t}=\rho y_{t-1}+u_{t}$ of size 244 , where $\rho=0.36$ in accordance with the persistence of real GDP growth and $u_{t} \sim N\left(0, \sigma^{2}\right)$ taking $\sigma$ different values to consider three variance regimes. The series $y_{t}$ has a first break after 126 periods and a second break after 220 (corresponding to the GM and GR dates, respectively). Let $\sigma_{1}^{2}=1.24$ be the variance before the firs break, $\sigma_{2}^{2}=0.24$ be the variance between the first and second break. Thus, this setting replicates our sample under the scenario that the GM existed (first break) and ended with the GR (second break). We test the null hypothesis that the GM holds

\footnotetext{
${ }^{25}$ Using BP, no break is found in $16.9 \%$ of times for 10 years and $41.5 \%$ for 15 years whereas, with IT, these percentages are higher $(35.2 \%$ and $68.8 \%$, respectively).

${ }^{26}$ From 1984.2 to 2007.4 , the standard deviation was 0.50 .

${ }^{27}$ To be precise, with BP, we identify the GM break in $96.9 \%, 91.8 \%$ and $77.8 \%$ of iterations for 5,10 and 15 years, respectively, while, in the rest of the cases, mainly, no break is found. Using IT, the 1984.2 break is detected in $93.2 \%, 82.5 \%$ and $70.3 \%$ of iterations for 5,10 and 15 years, respectively. In the rest, an additional break is found associated either with the GR or, mainly, after the GR recovery.
} 
against the alternative that it has disappeared either because the GR supposed a new break or because the first break disappeared. We let $\sigma_{3}^{2}=0.64$, which is the value after the GR. The percentage of rejections for the $I T$ and $B P$ test is 0.87 and 0.80 , respectively $(0.99$ and 0.95 if we increase 5 years the sample). Therefore, we can conclude that the tests work very well when we deal just with volatility. Thus, it seems that volatility is not enough to oust the GM; there is something else in the pre-GM data. We have an intuition that the shape of the recovery is what has allowed the return to low volatility after the GR. In the following section, we will carefully explore this question along with other features of the data.

\section{Feeble expansions: the price to pay for low volatility}

In the previous section, we have conducted Experiments 4 and 5, that is, to enlarge the original series by generating observations with the pre-GM characteristics and with the GR features combined with the pre-GM volatility, respectively. In order to have an intuition on the nature of the GM, we have randomly chosen one of the 10,000 series of Experiment 4 (where we enlarge the original series by generating observations with the pre-GM characteristics) and, from all the possible series of Experiment 5 (where we use the GR features combined with the pre-GM volatility), we have selected one of those that contains the highest number of recessions (in both cases, we consider a horizon of 15 years). Notice that this procedure plays against us and we intend to design the scenario that is most contrary to our arguments. A look at each of these series and their squared residuals allows us to observe that the same volatility comes from two very different paths (see Figure 3). On the one hand, the pre-GM series (blue line) reflects a steady increase of volatility that could be called "structural". On the other hand, the GR series normalized with the pre-GM volatility (red line) shows that the volatility increase with respect to the previous period comes from the number of times a recession worse than the last recession appears, which could be statistically interpreted as "outliers". Looking at Figure 3 (red line), we observe, in the immediate future, three deeper recessions than the last recession. Therefore, coming back 
to the postulated explanations of the GM, it seems acceptable to exclude good luck or even good policy as playing a primary role in an economy like the one presented in Figure 3. What kind of good luck or good policy provokes a deep recession every five years? It is worth noting that, in spite of these recessions, the economy still shows the characteristic features of the GM.

In addition, given the statistical evidence shown in the paper, it seems that the statements quoted in the Introduction, that linked the GM to the absence of recessions, could be misleading. In the simulated series of the GR (red line), even though the GM is there, the recessions are frequent and deep. The GM is clearly not linked either with the depth or the frequency of the recession periods. The fact that it is not linked to the frequency is clear in the data. In the simulated series we have, on average, a recession every five years and the GM still holds. With respect to the depth of the last recession, we carry out an exercise in which we compare the growth rate of the GDP series during the last recession with the growth rate of the pre-GM recessions. We compute a Wilcoxon rank sum test and find that we can not reject that the observations of the last recession come from the same distribution as those of the pre-GM recessions (the p-value being 0.61). Thus, in the simulated data, we have recessions with a higher frequency and the same depth as the pre-GM recessions and the GM still holds. We can clearly state that, contrary to the predominant opinion, the GM is only linked to the characteristics of expansion periods.

Trying to go deeper into the nature of the GM, the key question to investigate would be: which feature of the GM expansions makes them fundamentally different to the pre-GM ones? Some of the literature has concentrated on the new stylized facts of the latest expansions. The most relevant one is the shape of the recovery, because it has crucial implications for the stochastic properties of the GDP growth series, long-term economic activity and job creation capacity. The three-phase characterization of the business cycle consists of recession, highgrowth recovery -during which output reverts to its long-run trend- and moderate growth following the recovery. If the economy recovers quickly from its slump (V-shaped recession), 
the effect of the recession will be transitory and the economy will continue its long-run growth trend (the so-called "Friedman-plucking" effect). On the contrary, if the improvement occurs slowly (L- shaped recession), the effects may be permanent.

Some authors claim that the peak-reverting phase and, thus, the V-shaped expansions with intense job creation (as opposed to the apathetic pace of recoveries since the nineties which contribute to the sluggishness of job creation) disappeared after the mid-eighties. Camacho et al. (2011) document that this is a stylized fact after the GM and show how this change in business cycle dynamics can explain part of the GM as due to changes in inventory management brought about by improvements in information and communications technologies ${ }^{28}$. Furthermore, Ng and Wright (2013) identify, among other stylized facts, that the recoveries from the last three recessions are jobless recoveries. The last three recessions were characterized by productivity growth more than by increases in employment or hours worked. Stock and Watson (2012) provide insight into the phenomenon of jobless recoveries associated with the GR and show that, in a smoothly trending way, they were also visible in the recession of 2001. They show that they are due to a secular slowdown in the trend of labor force growth ${ }^{29}$. Gali et al. (2012) also acknowledge a different pattern in the three most recent recoveries, but they characterize them as low recoveries, as opposed to jobless recoveries, because they do not find evidence of structural change in the relation of employment and GDP during them.

However, the severity of an episode such as the GR, unprecedented in the GM times, leaves the door open to a possible transformation in the shape of recoveries. Previous papers only partially capture the last recession because of the lack of data, and they are basically biased towards gathering the features of the two recoveries of the GM. The idea is that the sluggish recoveries from the two recessions of the GM (prior to the last recession) were basically linked to the fact that these two recessions were mild. Therefore, a big recession

\footnotetext{
${ }^{28}$ Sichel (1994) and Kim and Murray (2002) documented the absence of the high growth phase after the 1990-1991 recession.

${ }^{29}$ With evidence prior to the last recession, Groshen and Potter (2003) and Schreft et al. (2005) also identify the sluggishness of job creation during the recoveries since the nineties.
} 
like the last one could have changed the shape of the recovery, returning to a shape similar to those of the period before the GM. This is clearly not the case. Even though we have suffered a recession that is comparable to the pre-GM recessions, the first year of the expansion (the recovery phase) is clearly different from the pre-GM ones, as can be seen in Figure 4, where we plot the average growth rate of GDP for each quarter after recession periods. As shown in the figure, the average growth rate during the first year exceeds the average growth rate during the second year (also for subsequent years, although they are not shown in the figure) for the pre-GM period, but is clearly below for the post GM-period. Nevertheless, it should be tested from a statistical point of view. We check this fact with the same test that we used for the recession periods, the Wilcoxon rank sum test. We clearly reject the null hypothesis that the first year of the last expansion is equal to the first year of the pre-GM expansions (p-value 0.02). However, this is not the case for the second and third years of the expansion periods, where we can clearly accept the null hypothesis that they are equal to those of the pre-GM periods.

To provide more evidence on whether the last US expansion is different from the previous ones, we propose an additional exercise. We select the data of GDP growth during expansions in three different periods: pre-GM, GM (only up to 2007.4) and GR. Taking nexp $p_{i}$ as the number of expansions in period $i$, with $i=1,2,3$, we select random sets of size $4 *$ nexp observations extracted through sampling replacement from the full set of expansion growth rates of period $i$ (being 4 , the number of quarters). For each set, we calculate the mean of the growth rate and we derive its empirical distribution considering 10,000 iterations. Then we compute the mean of US GDP growth rates of the first year of the recoveries for each period and we test whether the mean of each period belongs to its corresponding empirical distribution. Notice that, with this procedure, our aim is to test whether the distribution of the first year of recoveries is statistically different from the rest of recoveries.

In the case of the pre-GM period, the mean of the first years of the recoveries is 1.63 , with a p-value of 0.00 . In none of the 10.000 cases do we find a growth rate as high as 
the average growth rate of the first year of the recoveries. The empirical distribution of the mean of the growth rates of the expansion periods are plotted in Figure 5. As can be seen in the top plot, the mean growth rate of 1.63 is located just at the end of the right tail of the distribution. However, the results are completely different in the GM period. As can be seen in the middle plot, the average growth rate of the first year of the recoveries in this period is just 0.61 , and it is located in the left tail, while in the GR, it is right in the middle of the distribution (last plot). So, we can conclude that recoveries starting with high growth rates are typical of the pre-GM period and never occur after the GM.

The previous evidence shows that there is clearly something different in the current expansion with respect to the expansions of the pre-GM period, even though the recession periods are similar. As in standard GM expansions, we again have a weak recovery that implies that it will take a long time to get back to the levels of the GDP from before the last recession. But, to what extent this change in shape could be linked to the GM it is not clear.

In order to solve this final question, we propose two additional experiments: Experiment $6 a$ and Experiment $6 b$. In the first, we enlarge the sample for 15 years with the GR data (that include the recovery) using the previous bootstrap techniques but, every time that we have a recession, we substitute the next four quarters of the generated series with data extracted from the first four quarters of the pre-GM expansion periods ${ }^{30}$. The results are displayed in Table 7. As we can see, the GM only holds in $48.8 \%$ of the cases using the BP test (and 57.1\% with the IT). Remember that, in Experiment 3, when we enlarged the sample with GR data, the GM held in $100 \%$ of cases and, in Experiment 5, when we enlarged the sample adding the volatility of the pre-GM period, the GM still held in $77 . \%$ of the $\operatorname{cases}^{31}$. Thus, changing the recovery phases has a bigger effect on the end of the GM than increasing the volatility of the data. In Experiment $6 b$ we repeat the analysis of Experiment $6 a$ but incorporating the pre-GM volatility. In this case, we completely kill the GM: it only holds

\footnotetext{
${ }^{30}$ We identify the business cycle phases of the new sample through the Bry and Boschan (1971) method.

${ }^{31}$ Using the IT tests, the percentages are $86.7 \%$ and $69.8 \%$, respectively.
} 
in $9.6 \%$ and $2.3 \%$ of the cases with the BP and IT tests, respectively.

Therefore, although the GM was originally associated with a decrease in output volatility and was considered a great achievement in terms of reducing risk and of decreasing the frequency and the depth of recessions, which was, in turn, linked to good luck or good policy, after carefully analyzing the GM characteristics, they seem to be clearly associated with the shape of the expansions and, specifically, with the disappearance of high-growth recoveries. Perhaps, the benefits associated with an apparent increase of stability are paid for at a very high price. Feeble expansions are the price to pay for low volatility.

\section{Conclusions}

The global financial crisis of 2007 and the ensuing economic recession has prompted a debate on the possible end of the tranquil times of the GM. However, this paper presents evidence that the decrease in volatility associated with the GM seems to be quite a permanent phenomenon that holds in spite of the occurrence of further downturns in the characteristics of the GR or even of the fact that this may continue to extended horizons. The nature of the volatility reduction associated with the GM seems to be linked to the features of expansion phases, in particular, to the absence of high growth recoveries.

The fact that the GM holds even though we have suffered a strong recession, and the fact that it would hold even if we have this pattern of recession-recovery for a long time, should make us reconsider the explanations proposed in the literature about the causes of the GM, especially those related to good policy or good luck.

\section{References}

Ahmed, S., Levin, A., and Wilson, B. A. (2004). "Recent U.S. Macroeconomic Stability: Good Policies, Good Practices, or Good Luck?" The Review of Economics and Statistics, 86(3), 824832.

Alcala, F., and Sancho, I. (2004). "Output composition and the US output volatility decline." Economics Letters, 82(1), 115-120. 
Andrews, D. W. K. (1991). "Heteroskedasticity and autocorrelation consistent covariance matrix estimation." Econometrica, 59(3), 817-58.

Andrews, D. W. K. (1993). "Tests for parameter instability and structural change with unknown change point." Econometrica, 61(4), 821-56.

Andrews, D. W. K. (2003). "End-of-Sample Instability Tests." Econometrica, 71 (6), 1661-1694.

Andrews, D. W. K., and Ploberger, W. (1994). "Optimal tests when a nuisance parameter is present only under the alternative." Econometrica, 62(6), 1383-1414.

Bai, J., and Perron, P. (1998). "Estimating and testing linear models with multiple structural changes." Econometrica, 66(1), 47-78.

Bai, J., and Perron, P. (2003a). "Computation and analysis of multiple structural change models." Journal of Applied Econometrics, 18(1), 1-22.

Bai, J., and Perron, P. (2003b). "Critical values for multiple structural change tests." Econometrics Journal, 6(1), 72-78.

Bean, C. (2010). "Joseph Schumpeter Lecture The Great Moderation, The Great Panic, and The Great Contraction." Journal of the European Economic Association, 8(2-3), 289-325.

Bernanke, B. (2004). "The Great Moderation." Speech at the meetings of the Eastern Economic Association, Washington, D.C., February 20. http://www.federalreserve.gov/boarddocs/ speeches/2004/20040220/default.htm.

Blanchard, O. (2014). "Where Danger Lurks." Finance and Development, IMF, $51(3)$.

Blanchard, O., and Simon, J. (2001). "The Long and Large Decline in U.S. Output Volatility." Brookings Papers on Economic Activity, 32(1), 135-174.

Brunnermeier, M. K., Eisenbach, T., and Sannikov, Y. (2013). Macroeconomics with Financial Frictions: A Survey. New York: Cambridge University Press.

Brunnermeier, M. K., and Sannikov, Y. (2014). "A Macroeconomic Model with a Financial Sector." American Economic Review, 104(2), 379-421.

Bry, G., and Boschan, C. (1971). Cyclical Analysis of Time Series: Selected Procedures and Computer Programs. National Bureau of Economic Research, Inc.

Camacho, M., and Perez-Quiros, G. (2007). "Jump-and-Rest Effect of U.S. Business Cycles." Studies in Nonlinear Dynamics and Econometrics, 11(4), 1-39.

Camacho, M., Perez Quiros, G., and Rodriguez Mendizabal, H. (2011). "High-growth recoveries, inventories and the Great Moderation." Journal of Economic Dynamics and Control, 35(8), $1322-1339$.

Canova, F. (2009). "What Explains The Great Moderation in the U.S.? A Structural Analysis." Journal of the European Economic Association, 7(4), 697-721.

Canova, F., and Gambetti, L. (2010). "Do Expectations Matter? The Great Moderation Revisited." American Economic Journal: Macroeconomics, 2(3), 183-205. 
Chauvet, M., and Popli, G. (2008). "The Great Moderation Revisited: International Evidence." Mimeo, University of California Riverside.

Clark, T. E. (2009). "Is the Great Moderation over? an empirical analysis." Economic Review Federal Reserve Bank of Kansas City, Q IV, 5-42.

Coibion, O., and Gorodnichenko, Y. (2011). "Monetary Policy, Trend Inflation, and the Great Moderation: An Alternative Interpretation." American Economic Review, 101(1), 341-70.

Davis, S. J., and Kahn, J. A. (2008). "Interpreting the Great Moderation: Changes in the Volatility of Economic Activity at the Macro and Micro Levels." Journal of Economic Perspectives, 22(4), $155-80$.

Deng, A., and Perron, P. (2008). "The Limit Distribution Of The Cusum Of Squares Test Under General Mixing Conditions." Econometric Theory, 24(03), 809-822.

Fagiolo, G., Napoletano, M., and Roventini, A. (2008). "Are output growth-rate distributions fattailed? some evidence from OECD countries." Journal of Applied Econometrics, 23 (5), 639-669.

Gali, J., and Backus, D. K. (1999). "International Factors in the Recessions of the Early Nineties." In R. Sato, R. V. Ramachandran, and K. Mino (Eds.), Global Integration and Competition, vol. 4, Springer US.

Gali, J., and Gambetti, L. (2009). "On the Sources of the Great Moderation." American Economic Journal: Macroeconomics, 1(1), 26-57.

Gali, J., Smets, F., and Wouters, R. (2012). "Slow Recoveries: A Structural Interpretation." Journal of Money, Credit and Banking, 44, 9-30.

Giannone, D., Lenza, M., and Reichlin, L. (2008). "Explaining The Great Moderation: It Is Not The Shocks." Journal of the European Economic Association, 6(2-3), 621-633.

Groshen, E. L., and Potter, S. (2003). "Has structural change contributed to a jobless recovery?" Current Issues in Economics and Finance, 9(8).

Hansen, B. E. (1997). "Approximate Asymptotic P Values for Structural-Change Tests." Journal of Business and Economic Statistics, 15(1), 60-67.

Herrera, A. M., and Pesavento, E. (2005). "The Decline in U.S. Output Volatility: Structural Changes and Inventory Investment." Journal of Business and Economic Statistics, 23, 462-472.

Inclán, C., and Tiao, G. C. (1994). "Use of cumulative sums of squares for retrospective detection of changes of variance." Journal of the American Statistical Association, 89(427), 913-923.

Inoue, A., and Rossi, B. (2011). "Identifying the Sources of Instabilities in Macroeconomic Fluctuations." The Review of Economics and Statistics, 93(4), 1186-1204.

Justiniano, A., Primiceri, G. E., and Tambalotti, A. (2010). "Investment shocks and business cycles." Journal of Monetary Economics, 57(2), 132-145. 
Keating, J. W., and Valcarcel, V. J. (2012). "What's so Great about the Great Moderation? A Multi-Country Investigation of Time-Varying Volatilities of Output Growth and Inflation." Working Paper Series in Theoretical and Applied Economics 201204, University of Kansas, Department of Economics.

Kim, C.-J., and Murray, C. J. (2002). "Permanent and transitory components of recessions." Empirical Economics, 27(2), 163-183.

Kim, C.-J., and Nelson, C. R. (1999). "Has The U.S. Economy Become More Stable? A Bayesian Approach Based On A Markov-Switching Model Of The Business Cycle." The Review of Economics and Statistics, 81(4), 608-616.

Lucas, R. E. J. (2003). "Macroeconomic Priorities." American Economic Review, 93(1), 1-14.

McConnell, M. M., and Perez-Quiros, G. (2000). "Output Fluctuations in the United States: What Has Changed since the Early 1980's?" American Economic Review, 90(5), 1464-1476.

Ng, G. C., and Tambalotti, A. (2012). "The Great Moderation, Forecast Uncertainty, and the Great Recession." Federal Reserve Bank of New York, Blog.

Ng, S., and Wright, J. H. (2013). "Facts and Challenges from the Great Recession for Forecasting and Macroeconomic Modeling." Journal of Economic Literature, 51(4), 1120-54.

Politis, D., and Romano, J. (1994). "The stationary bootstrap." Journal of the American Statistical Association, 89, 1303-1313.

Sanso, A., Arago, V., and i Silvestre, J. L. C. (2004). "Testing for changes in the unconditional variance of financial time series." Revista de Economia Financiera, 4, 32-53.

Schreft, S. L., Singh, A., and Hodgson, A. (2005). "Jobless recoveries and the wait-and-see hypothesis." Economic Review, Q IV, 81-99.

Sichel, D. E. (1994). "Inventories and the three phases of the business cycle." Journal of Business and Economic Statistics, 12(3), 269-77.

Stock, J. H. (2015). "The Slowdown in GDP Growth: Decomposition and Some Implications." Harvard Macroeconomic Policy Seminar.

Stock, J. H., and Watson, M. W. (1998). "Median Unbiased Estimation of Coefficient Variance in a Time-Varying Parameter Model." Journal of the American Statistical Association, 93(441), 349-358.

Stock, J. H., and Watson, M. W. (2002). "Has the business cycle changed and why?" NBER Working Papers 9127, National Bureau of Economic Research, Inc.

Stock, J. H., and Watson, M. W. (2005). "Understanding changes in international business cycle dynamics." Journal of the European Economic Association, 3(5), 968-1006.

Stock, J. H., and Watson, M. W. (2012). "Disentangling the Channels of the 2007-2009 Recession." Brookings Papers on Economic Activity, Spring, 81-135.

Summers, L. H. (2014). "U.S. Economic Prospects: Secular Stagnation, Hysteresis, and the Zero Lower Bound." Business Economics, 49(2), 65-73. 
Summers, P. M. (2005). "What caused the Great Moderation?: some cross-country evidence." Economic Review Federal Reserve Bank of Kansas City, Q III, 5-32.

Taylor, J. B. (2011). "Macroeconomic Lessons from the Great Deviation." In NBER Macroeconomics Annual 2010, Volume 25, NBER Chapters, 387-395, National Bureau of Economic Research, Inc.

Taylor, J. B. (2012). "The Great Deviation." In E. F. Koenig, R. Leeson, and G. A. Kahn (Eds.), The Taylor Rule and the Transformation of Monetary Policy, Book Chapters, chap. 7, Hoover Institution, Stanford University.

Vine, D. J., and Ramey, V. A. (2006). "Declining Volatility in the U.S. Automobile Industry." American Economic Review, 96 (5), 1876-1889.

Williams, J. C., and Taylor, J. B. (2009). "A black swan in the money market." American Economic Journal: Macroeconomics, 1(1), 58-83.

Zhou, J., and Perron, P. (2008). "Testing for Breaks in Coefficients and Error Variance: Simulations and Applications." Working Papers Series wp2008-010, Boston University - Department of Economics. 


\section{Tables}

TABLE 1

STRUCTURAL BREAKS IN VARIANCE

\begin{tabular}{cccc}
\hline \hline Null & Sup & Exp & Ave \\
\hline$\sigma_{1}^{2}=\sigma_{2}^{2}$ & 15.70 & 5.28 & 7.05 \\
& $(0.003)$ & $(0.000)$ & $(0.003)$
\end{tabular}

Estimated break data 1984.2

Notes: We test for changes in variance in the following regression: $\Delta y_{t}=\mu+\phi \Delta y t-1+\varepsilon_{t}, \varepsilon_{t} \sim-N\left(0, \sigma_{t}^{2}\right)$ where $\sigma_{t}^{2}=\sigma_{1}^{2}$ if $t \leq T$ and $\sigma_{t}^{2}=\sigma_{2}^{2}$ if $>T$. We use structural break tests based on Andrews (1993), Andrews and Ploberger (1994) and McConnell and Perez-Quiros (2000).

TABLE 2

Multiple structural Breaks (BAi-Perron methodology)

\begin{tabular}{ccc|cc}
\hline \hline & Model 1 & Model 2 & \multicolumn{2}{c}{ Critical values } \\
\hline supF_(k) & & & $5 \%$ & $1 \%$ \\
$\mathrm{k}=1$ & 5.98 & 6.30 & 9.10 & 13.00 \\
$\mathrm{k}=2$ & 7.55 & 6.58 & 7.92 & 10.14 \\
$\mathrm{k}=3$ & 6.80 & 3.12 & 6.84 & 8.42 \\
$\mathrm{supF}_{-}(\mathrm{l}+1 / \mathrm{l})$ & & & & \\
$\mathrm{l}=1$ & 0.99 & 0.88 & 9.10 & 9.10 \\
$\mathrm{l}=2$ & 4.70 & 5.31 & 10.55 & 10.55 \\
\hline $\mathrm{UDmax}$ & 7.55 & 6.57 & 9.52 & 9.52 \\
WDmax & 9.04 & 8.15 & 13.07 & 13.07 \\
\hline $\mathrm{T}$ (SBIC) & 0 & 0 & & \\
$\mathrm{~T}$ (LWZ) & 0 & 0 & & \\
\hline $\mathrm{T}$ (sequential) & 0 & 0 & & \\
\hline \hline
\end{tabular}

Notes: We look for changes in the mean in a pure structural model (Model 1) and including an autoregressive (Model 2). The trimming parameter is $\epsilon=0.10$ and the maximum number of breaks is 3 . Serial correlation and heterogeneity in the errors are allowed. The consistent covariance matrix is constructed using the Andrews (1991) method. 
TABLE 3

TIME-VARIANT TREND GROWTH

\begin{tabular}{|c|c|c|c|c|c|}
\hline \multicolumn{6}{|c|}{ Median-Unbiased estimates, test of $\lambda=0$} \\
\hline Test & Statistic (p-value) & $\hat{\lambda}$ & $90 \% \mathrm{CI}$ & $\widehat{\sigma}_{\Delta \beta}$ & $90 \% \mathrm{CI}$ \\
\hline $\mathrm{L}$ & $0.3828(0.0800)$ & 6.9123 & $(0,27.81)$ & 0.0361 & $(0,0.15)$ \\
\hline MW & $2.4802(0.0750)$ & 7.2602 & $(0,30.15)$ & 0.0379 & $(0,0.16)$ \\
\hline EW & $1.4052(0.1100)$ & 5.9698 & $(0,23.83)$ & 0.0312 & $(0,0.12)$ \\
\hline QLR & $5.5885(0.1850)$ & 4.9095 & $(0,20.63)$ & 0.0256 & $(0,0.11)$ \\
\hline $\mathrm{POI}(7)$ & $4.3795(0.1650)$ & 4.9599 & $(0,17.22)$ & 0.0259 & $(0,0.09)$ \\
\hline $\mathrm{POI}(17)$ & $9.0164(0.3250)$ & 3.4067 & $(0,14.03)$ & 0.0178 & $(0,0.07)$ \\
\hline \multicolumn{6}{|c|}{ Parameter estimates } \\
\hline & MMLE & MPLE & $\sigma_{\Delta \beta}=0.04$ & $\sigma_{\Delta \beta}=0.15$ & \\
\hline$\sigma_{\Delta \beta}$ & 0.0150 & 0.0000 & 0.0400 & 0.1500 & \\
\hline$\sigma_{\epsilon}$ & 0.8371 & 0.8386 & 0.8352 & 0.8203 & \\
\hline$\phi_{1}$ & 0.3265 & 0.3305 & 0.3235 & 0.3036 & \\
\hline$\phi_{2}$ & 0.1170 & 0.1124 & 0.1087 & 0.1019 & \\
\hline$\phi_{3}$ & -0.0555 & -0.0673 & -0.0723 & -0.0753 & \\
\hline$\phi_{4}$ & -0.0418 & 0.0000 & 0.0000 & 0.0000 & \\
\hline$\beta_{0}$ & & 0.7533 & 0.8185 & 0.7068 & \\
\hline
\end{tabular}

Notes: $L, M W, E W, Q L R, P O I(7), P O I(17)$ are the battery of median-unbiased estimates of $\lambda$ proposed by Stock and Watson (1998). MMLE, MPLE and the two models with fixed values of $\sigma_{\Delta \beta},(0.04,0.15)$, estimate the parameters of equation (10).

TABLE 4

Detecting Changes in VARIANCE

\begin{tabular}{|c|c|c|c|c|}
\hline \multicolumn{2}{|c|}{ ICSS algorithm } & \multicolumn{2}{|c|}{ Bai-Perron } & McConnell-Perez-Quiros \\
\hline$I T\left(\kappa_{1}\right)$ & $I T\left(\kappa_{2}\right)$ & Model 1 & Model 2 & \\
\hline \multicolumn{5}{|c|}{ ORIGINAL SERIES } \\
\hline 1984.2 & 1984.2 & 1984.2 & 1983.4 & 1984.2 \\
\hline \multicolumn{5}{|c|}{ FILTERED SERIES } \\
\hline \multicolumn{5}{|c|}{ MMLE } \\
\hline 1984.2 & 1984.2 & 1984.2 & 1983.4 & 1984.2 \\
\hline \multicolumn{5}{|c|}{ MPLE } \\
\hline 1984.2 & 1984.2 & 1984.2 & 1983.4 & 1984.2 \\
\hline \multicolumn{5}{|c|}{$\sigma_{\Delta \beta}=0.04$} \\
\hline 1984.2 & 1984.2 & 1984.2 & 1983.4 & 1984.2 \\
\hline \multicolumn{5}{|c|}{$\sigma_{\Delta \beta}=0.15$} \\
\hline 1984.1 & 1984.1 & 1984.2 & 1983.4 & 1984.2 \\
\hline
\end{tabular}

Notes: Filtered series have been obtained by removing the trend growth rates based on the time-varying parameter $\beta_{t}$ estimated with the different methods. 
TABLE 5

Detecting changes in variance (Bai-Perron)

\begin{tabular}{|c|c|c|c|c|c|c|}
\hline \multirow[b]{3}{*}{ Experiment 1} & \multirow[t]{2}{*}{ GM SB } & \multirow[t]{2}{*}{ No SB } & \multirow[t]{2}{*}{ Random SB(s) } & \multicolumn{2}{|c|}{ GM SB } & \multirow[t]{2}{*}{ GM SB + GR SB } \\
\hline & & & & +1 random $\mathrm{SB}$ & +2 random $\mathrm{SB}$ & \\
\hline & 92.6 & & 7.4 & & & \\
\hline Experiment 2 & 90.9 & 8.9 & & 0.1 & & \\
\hline \multicolumn{7}{|l|}{ Experiment 3} \\
\hline 5 years & 100.0 & & & 0.0 & & \\
\hline 10 years & 100.0 & & & 0.0 & & \\
\hline 15 years & 100.0 & & & 0.0 & & \\
\hline Experiment 4 & & & & GR & & \\
\hline 5 years & 68.0 & 1.4 & & 1.4 & & 29.2 \\
\hline 10 years & 24.2 & 17.3 & & 10.0 & 0.0 & 48.5 \\
\hline 15 years & 5.6 & 41.4 & 0.0 & 12.8 & 0.1 & 40.1 \\
\hline \multicolumn{7}{|l|}{ Experiment 5} \\
\hline 5 years & 96.9 & 3.0 & & 0.0 & & 0.0 \\
\hline 10 years & 91.8 & 8.1 & & 0.0 & & 0.1 \\
\hline 15 years & 77.8 & 19.1 & & 0.5 & & 2.7 \\
\hline
\end{tabular}

TABLE 6

Detecting changes in variance (ICSS algorithm IT(k2))

\begin{tabular}{|c|c|c|c|c|c|c|}
\hline \multirow[b]{3}{*}{ Experiment 1} & \multirow[t]{2}{*}{$\overline{~ G M ~ S B}$} & \multirow[t]{2}{*}{ No SB } & \multirow{2}{*}{ Random SB(s) } & \multicolumn{2}{|c|}{ 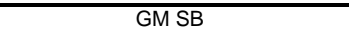 } & \multirow{2}{*}{ 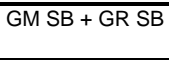 } \\
\hline & & & & + 1 random SB & +2 random $\mathrm{SB}$ & \\
\hline & 92.6 & & 7.4 & & & \\
\hline Experiment 2 & 89.4 & & 9.1 & 1.4 & & 0.1 \\
\hline Experiment 3 & & & $1996.1 \& 2000.2$ & & & \\
\hline 5 years & 76.0 & & 24.0 & & & \\
\hline 10 years & 63.2 & & 36.8 & & & \\
\hline 15 years & 86.7 & & 13.2 & & & \\
\hline Experiment 4 & & & & GR & & \\
\hline 5 years & 77.3 & 4.7 & 2.2 & 0.4 & & 15.5 \\
\hline 10 years & 15.1 & 35.2 & 8.2 & 9.1 & 0.1 & 32.4 \\
\hline 15 years & 1.5 & 68.8 & 3.9 & 8.9 & 0.1 & 16.8 \\
\hline Experiment 5 & & & & GR recovery & & \\
\hline 5 years & 93.2 & 0.0 & 0.1 & 3.2 & & 3.5 \\
\hline 10 years & 81.3 & 0.1 & 0.2 & 14.2 & 0.2 & 4.1 \\
\hline 15 years & 69.8 & 0.1 & 0.4 & 21.3 & 0.1 & 8.3 \\
\hline
\end{tabular}

Note: To date the structuctural breaks (SB) associated with the GM and the GR, we consider an interval of 4 quarters around 1984.2 and 2007.4.

TABLE 7

Experiment 6 (15 years)

\begin{tabular}{|c|c|c|c|c|c|c|}
\hline & \multirow[t]{2}{*}{ GM SB } & \multirow[t]{2}{*}{ No SB } & \multirow[t]{2}{*}{ Random SB(s) } & \multicolumn{2}{|c|}{ GM SB } & \multirow[t]{2}{*}{ GM SB + GR SB } \\
\hline & & & & +1 random $\mathrm{SB}$ & +2 random $\mathrm{SB}$ & \\
\hline \multicolumn{7}{|c|}{ Detecting changes in variance (Bai-Perron) } \\
\hline & & & & GR and recovery & & \\
\hline GR (Exp 3) & 100.0 & & & & & \\
\hline GR+vol (Exp 5) & 77.3 & 18.7 & & 0.5 & & 3.5 \\
\hline GR+Hrec & 48.8 & 4.6 & & 25.0 & 0.5 & 21.1 \\
\hline $\mathrm{GR}+\mathrm{Hrec}+\mathrm{vol}$ & 9.6 & 74.0 & 0.1 & 10.2 & & 6.1 \\
\hline \multicolumn{7}{|c|}{ Detecting changes in variance (ICSS algorithm IT(k2)) } \\
\hline & & & & GR and recovery & & \\
\hline GR (Exp 3) & 86.6 & & 13.4 & & & 0.0 \\
\hline GR+vol (Exp 5) & 67.1 & & 0.2 & 25.6 & 0.3 & 6.8 \\
\hline GR+Hrec & 57.1 & 34.7 & 6.5 & 1.5 & & 0.2 \\
\hline $\mathrm{GR}+\mathrm{Hrec}+\mathrm{vol}$ & 2.1 & 87.6 & 0.1 & 7.8 & 0.3 & 2.1 \\
\hline
\end{tabular}

Note: To date the structural breaks (SB) associated with the GM and the GR, we consider an interval of 4 quarters around 1984.2 and 2007.4. 


\section{Figures}

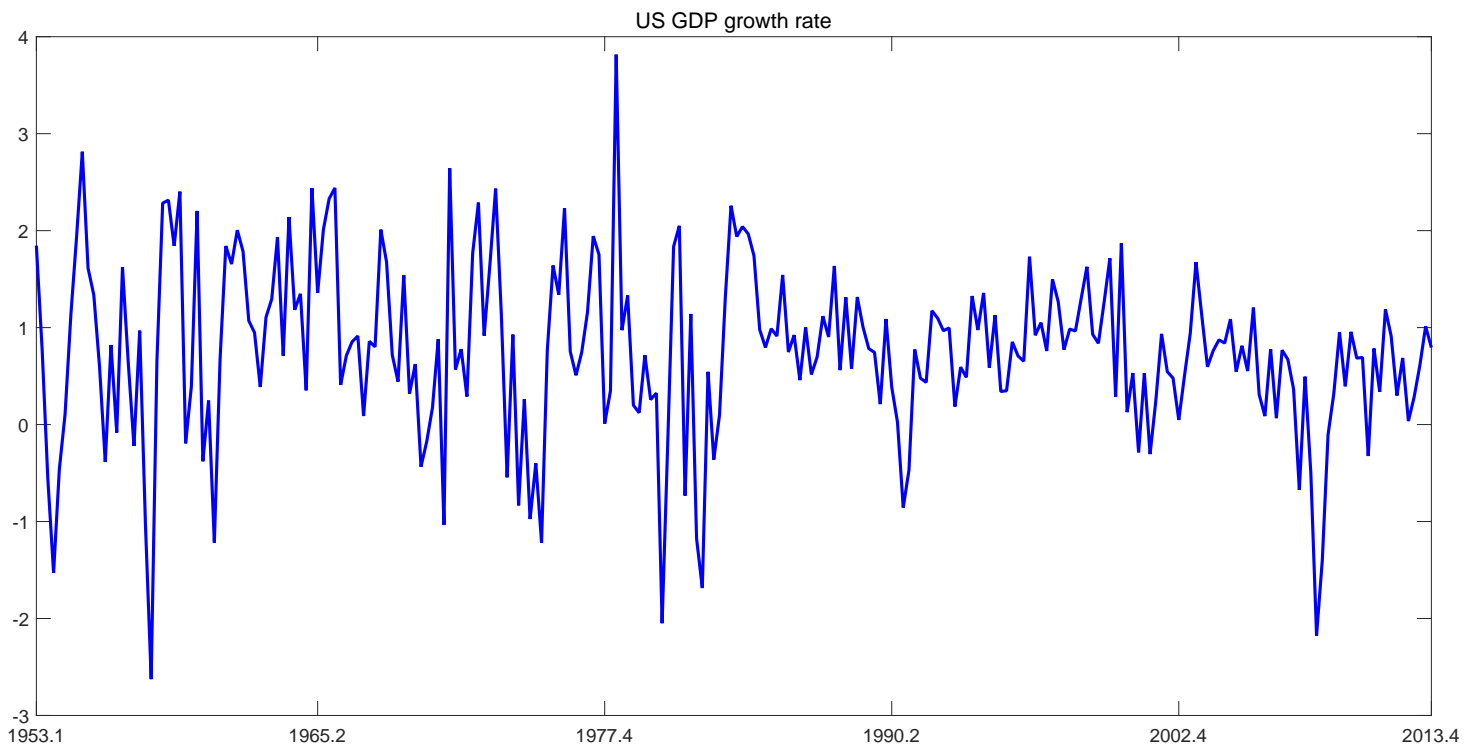

FiguRE 1. US GDP Growth Rate

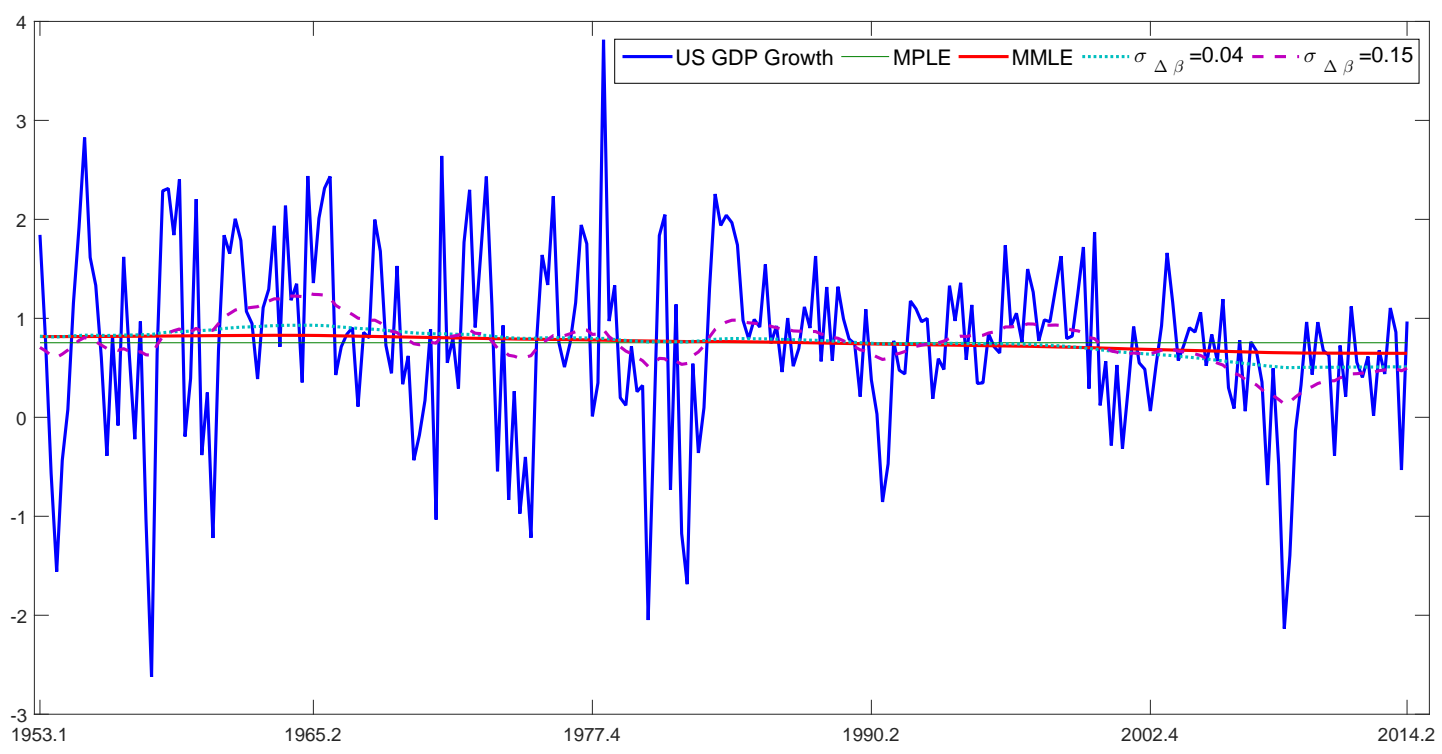

FIGURE 2. US GDP Growth and estimated trends 


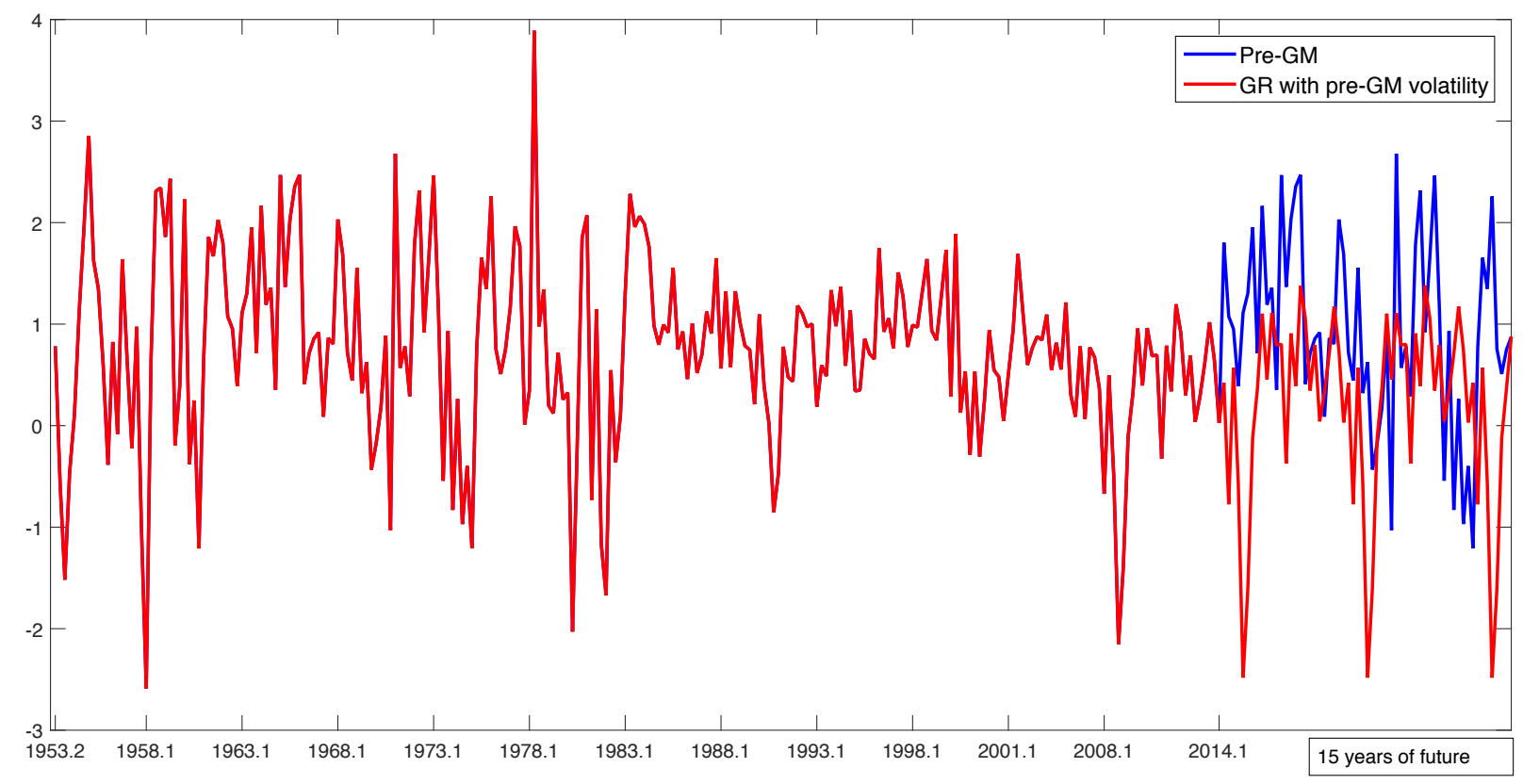

(a) GDP growth rates
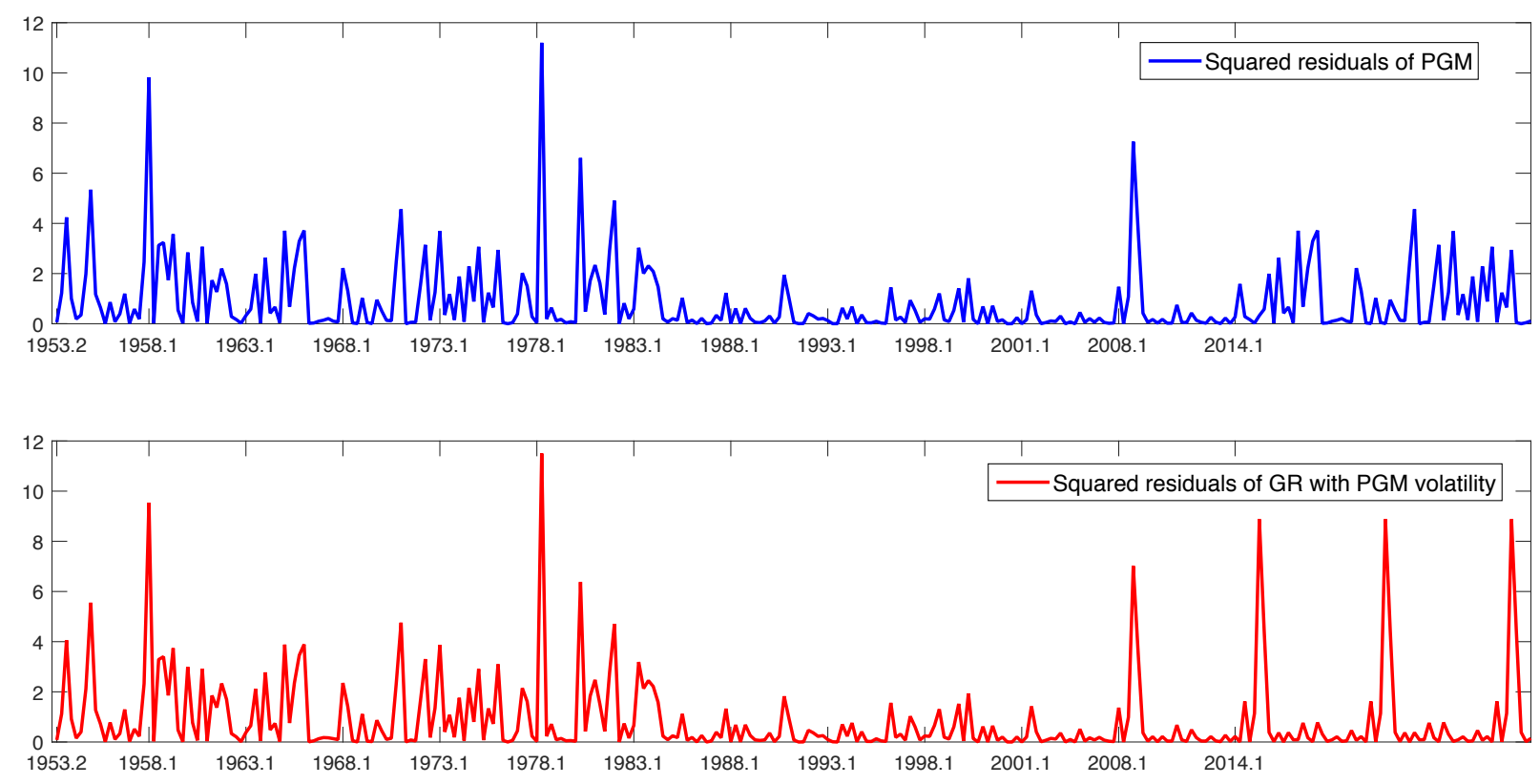

(b) Squared residuals

FiguRE 3. Illustration of different scenarios (15 years)

Notes: The figure plots the GDP growth rates and their squared residuals expanding the sample for 15 years under Experiments 4 (blue lines) and 5 (red lines). 


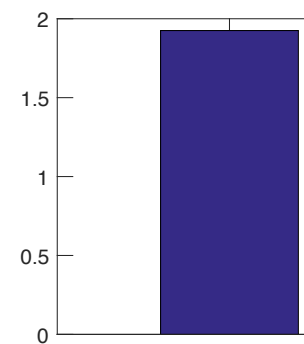

Q1

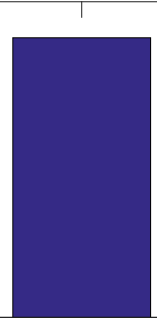

Q2

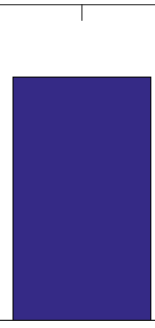

Q3

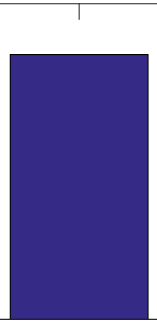

Q4

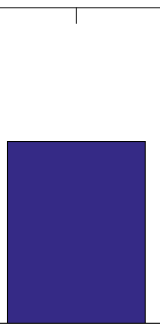

Q5

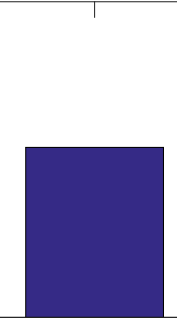

Q6

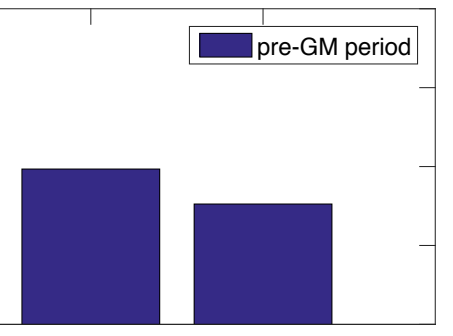

Q7

Q8

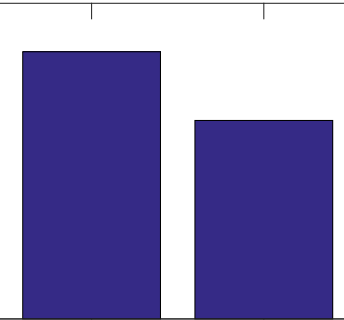

Q7

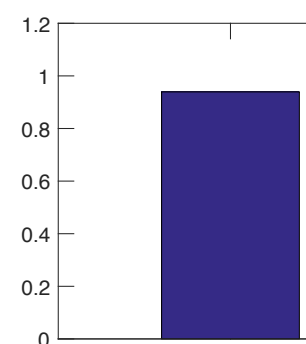

Q1

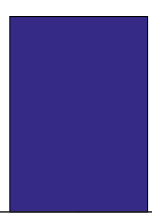

Q2

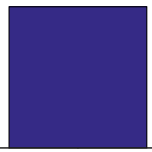

Q3

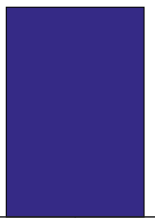

Q4

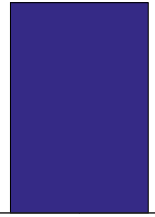

Q5
Q6
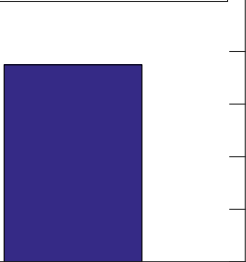

Q8

FiguRE 4. Average quarterly real GDP growth in the first two years of expansions
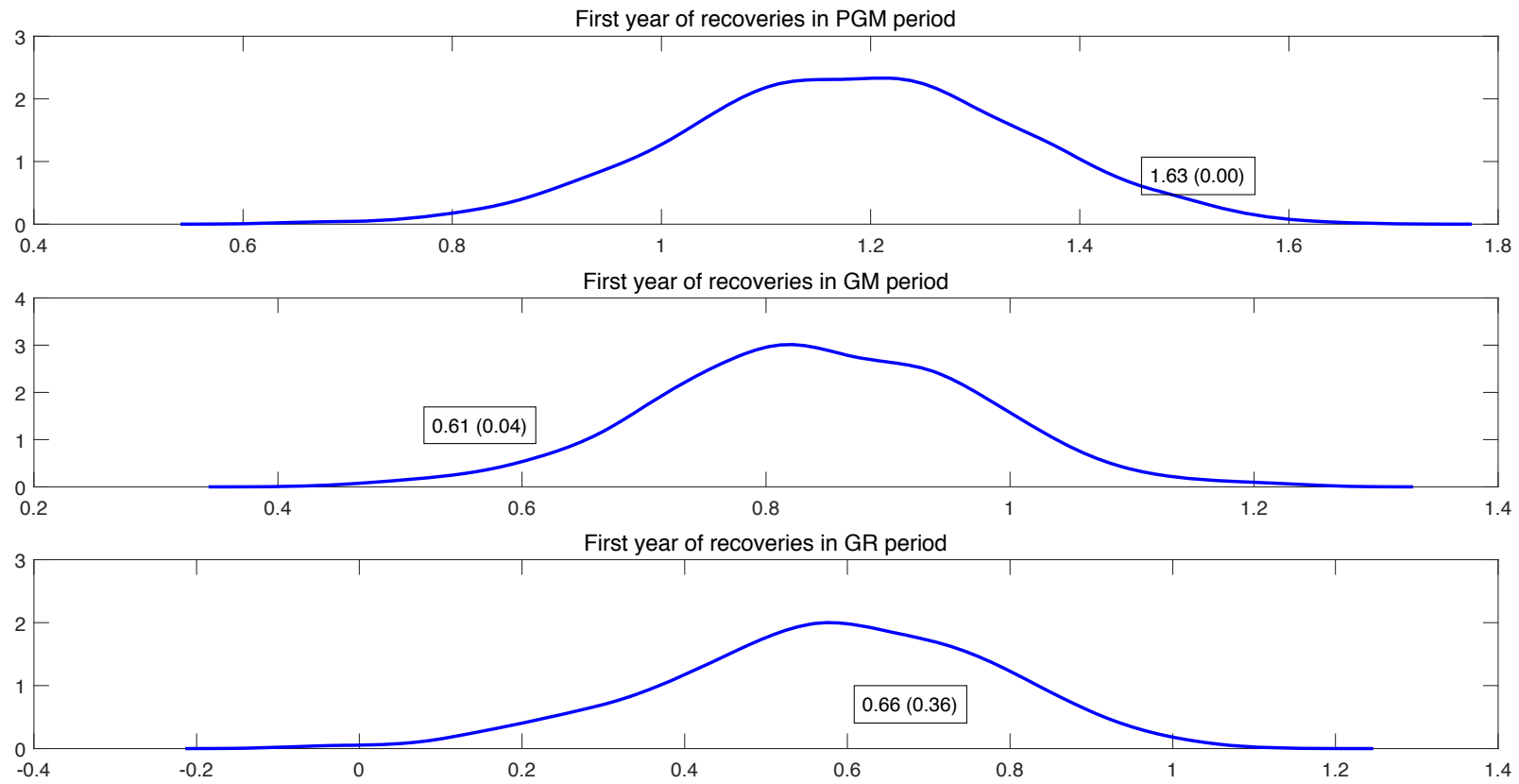

FiguRE 5. Distribution of the GDP growth rate during the first year of recoveries (simulations) 